\title{
Visual Acuity and Refractive Error Improvement in Keratoconic Patients: A Low-Income Context Management Perspective
}

This article was published in the following Dove Press journal: Clinical Optometry

\author{
Walter Kibet Yego (D) \\ Vanessa Raquel Moodley (D) ${ }^{2}$ \\ 'Department of Optometry and Vision \\ Sciences, Masinde Muliro University of \\ Science and Technology, Kakamega, \\ Kenya; ${ }^{2}$ Department of Optometry, \\ University of KwaZulu-Natal, Durban, \\ South Africa
}

Introduction: Visual acuity (VA) and refractive error (RE) remain important parameters in the management of keratoconic (KC) patients. Despite rapid amelioration in capacity of diagnostic equipment, these remain inaccessible to the majority of practitioners in lowincome countries. Notwithstanding limitations, practitioners are expected to utilize existing resources to satisfactorily manage their increasing numbers of keratoconic patients.

Purpose: To determine the changes in visual acuity and refractive errors with diagnostic and management options available in low-income contexts.

Methods: A descriptive, retrospective chart analysis of medical records dating back 5 years was employed in this study. Records of patients prescribed with corneal rigid gas permeable (RGP) and scleral lenses were analyzed. Data on age, gender, stage of keratoconus, pre-, and post-visual acuities and refractive errors, mode of correction and lens parameters were evaluated.

Results: A total of 124 medical records were analyzed. Males comprised $58.9 \%$ and females $41.1 \%$ of the total sample, with a mean age $20.86 \pm 9.50$ years. The mean unaided VA in $\log$ MAR notation was $1.0 \pm 0.19$, while corrected VA was $0.18 \pm 0.17$. There was a significant

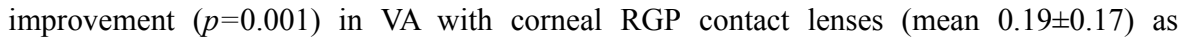
compared to unaided VA (mean 1.29 \pm 0.20 ). Scleral lens VA also improved from a median of 1.06 to $-0.01 \operatorname{logMAR} ; p=0.001$. The mean RE before RGP contact lens fitting was -9.43 \pm 2.37 diopters (D) which improved to $-0.41 \pm 0.78 \mathrm{D}$. RE reduced significantly $(p=0.001)$ after fitting with both corneal RGP lenses (from a mean of $-9.80 \pm 4.46 \mathrm{D}$ to $-0.45 \pm 0.80 \mathrm{D}$ ) and scleral lenses (from a median of $-8.00 \mathrm{D}$ to $-0.02 \mathrm{D}$ ).

Conclusion: Significantly improved visual acuity and refractive error status were achieved with all KC patients. Despite the diagnostic equipment and contact lenses design limitations, practitioners in low-income contexts can fit the relatively more affordable corneal RGP lenses to positively impact the daily living experiences of their $\mathrm{KC}$ patients.

Keywords: keratoconus, cornea, visual outcomes, rigid gas permeable, scleral lenses, myopia

\section{Introduction}

Visual acuity and refractive error are key components addressed in the management of keratoconic patients due to their potential negative impact on the quality of life of the afflicted individual. Keratoconus (KC) is a pan-corneal, non-inflammatory ectasia affecting the inferior paracentral corneal stroma that leads to a conicalshaped cornea, corneal thinning and irregular astigmatism. ${ }^{1,2}$ The onset of the condition is common in the first or second decade of life, progressing until the
Correspondence: Walter Kibet Yego Department of Optometry and Vision Sciences, Masinde Muliro University of Science and Technology, Kakamega, Kenya Tel +254724891819

Email drkibetwalter@gmail.com
Clinical Optometry 2020:12 II3-122 
third or fourth decade before regaining stability. ${ }^{3,4}$ The extent of the progression depends on the interplay between the environmental context, genetic factors, time of onset as well as diagnostic and intervention methods used. ${ }^{5,6}$

The prevalence of $\mathrm{KC}$ has been reported in multiple countries, including the United States (500 cases per 100,000 people), Japan ( 9 per 100,000 people), India (2300 per 100,000 people), Israel (2340 per 100,000 people), Macedonia ( 7 per 100,000 people), Iran (2400 per 100,000 people), the Netherlands (13,300 per 100000 people), China (27 per 100,000 people) and Egypt (170 per 100 000). ${ }^{6}$ Medical record reviews in clinicalbased studies conducted in sub-Saharan Africa suggest a range of 70-300 patients seen over an average period of 5 years. $^{7-9}$ Although there has never been a national prevalence study conducted in Kenya, anecdotal reports from practitioners suggest an increasing incidence. A single facility-based study that analyzed the characteristics of $254 \mathrm{KC}$ cases reported children as young as 6 years-old presenting with clinical signs. ${ }^{9}$ Further, Chen et $\mathrm{al}^{10}$ reported $\mathrm{KC}$ as the leading cause of corneal transplantation and other surgical interventions in Kenya.

Although the actual cause of keratoconus remains unknown, studies to establish the etiology investigated family history, ethnicity and environmental precipitating factors such as high temperatures and food allergies. ${ }^{4,11}$ Cited risk factors include individual gene composition, ultraviolet and sun exposure, eye rubbing, gender, hormonal variation, age, atopy, floppy eyelid syndrome and parental education. ${ }^{4,6,12}$ In addition, connective tissue disorders such as Ehler-Danlos syndrome, Marfan syndrome, Lonstein disease, Down syndrome and mitral valve prolapse are the most common associated disease conditions. ${ }^{6}$

There is a huge disparity in access to eye care services, diagnostic equipment and management options between low- and high-income countries. ${ }^{13}$ In low-income settings, the basic clinical equipment employed to diagnose keratoconus largely remains the slit lamp, ophthalmoscope, keratometer and retinoscope. Keratoconus is graded by keratometry readings and the presence of slit-lamp biomicroscopic signs such as corneal thinning, Munson's sign, Fleischer's ring, Vogt striae, corneal hydrops and localized inferior paracentral protrusion. ${ }^{14}$ The retinoscopy signs include a distorted scissor reflex and fluctuating refractive end point while ophthalmoscopic signs include an oil droplet reflex (Charleux sign) and reduced anterior chamber visibility. ${ }^{11,15}$ Diagnosing KC has been significantly aided by the introduction of equipment such as corneal topographers and tomographers, used widely in highincome countries to diagnose and manage KC. However, in low-income countries, keratometers still remain the most widely utilized equipment to quantify and grade the abnormal corneal profile in initial diagnosis (values greater than 47 diopters) and to monitor disease progression. ${ }^{16}$

The more sophisticated equipment possess advanced technological features and algorithms capable of detecting the earliest changes in the corneal structure, determining contact lens parameters, simulating contact lens fit and informing decisions during corneal surgeries. ${ }^{17}$ Sharma et $\mathrm{al}^{18}$ reported that the majority of the young population presenting with $\mathrm{KC}$ risk factors, such as ocular allergies and frequent eye rubbing, live in tropical regions of subSaharan Africa and best practices indicate concurrent investigation for $\mathrm{KC}$. The gold-standard tomographers enable pre-clinical diagnosis, potentially promoting timeous management interventions to delay or prevent the need for surgical interventions. Applying the best practice protocol of early detection to retard disease progression is limited in most developing context practices, as high costs prevent the advanced equipment from being generally available. ${ }^{14}$ Practitioners in these countries still have the ethical and clinical responsibility to utilize available resources to diagnose and manage presenting keratoconic patients.

The treatment of $\mathrm{KC}$ is targeted at eliminating irregular refraction on the corneal surface by using spectacle corrections, specialized spherical soft contact lenses, soft toric contact lenses, rigid contact lenses and corneal surgeries. ${ }^{19}$ Spectacles and soft contact lenses may provide sufficient vision in the incipient stage whilst rigid corneal contact lenses become effective in moderate to advanced stages. There is also increasing use of specialized contact lenses such as hybrid and scleral lenses for advanced and severe KC. An ideal preventative strategy, that has become a standard treatment option in high-income countries, involves early detection and timeous management with corneal crosslinking (CXL) to retard progression. ${ }^{20}$ In low-income settings, however, spectacles and corneal rigid gas permeable (RGP) contact lenses are the most commonly prescribed, as specialized lenses and CXL remain unaffordable for most patients.

The low gross domestic product, compounded by competing national priorities such as housing and education, results in national spending on health care being meagre in low-income countries, as compared to high-income settings. ${ }^{13}$ The disparity in economic situations remains 
a precipitating factor in the varying diagnostic and management strategies employed in eye health care. If one considers the costs of eye care services and appliances as a proportion of the average income, one finds that they are much higher in low as opposed to high-income countries ${ }^{21-26}$ (Table 1).

Framed within the low-income practicing context, most practitioners will finalize diagnosis and determine the management plan after conducting a refraction using the retinoscope and trial lens and frame set, taking corneal measurements with a keratometer and examining the eye using a slit lamp biomicroscope. The additional pre-trial lens fitting measurements such as horizontal visible iris diameter, palpebral aperture size, pupil diameter and tear function tests are generally used to determine the corneal RGP contact lenses of first choice, rather than a hybrid or scleral lens. The wide use of corneal RGP lenses as part of the standard fitting protocol is informed by both availability and affordability of these lenses compared to hybrid and scleral lenses. ${ }^{9}$ Practitioners make these choices despite literature indications that they could obtain better comfort, vision and ocular health, in cases of extremely steep corneal contours, if specialized contact lenses are prescribed. ${ }^{27,28}$ Evidence of the impact of the interventions made by practitioners forced to diagnose and manage $\mathrm{KC}$ patients within resource-limited contexts, is however lacking. Hence, the study aimed to determine whether practitioners are able to achieve satisfactory refractive and visual outcomes for their $\mathrm{KC}$ patients, noting the limitations in the availability of high technology equipment and costly corrective devices.

\section{Materials and Methods}

Utilizing a quantitative, retrospective chart review design, records of keratoconus patients who attended a specialist

Table I The Average Income and Economic Spend for Healthcare and Eye Care Costs in the Two Economic Settings

\begin{tabular}{|l|l|l|}
\hline Indices & $\begin{array}{l}\text { High-Income } \\
\text { Countries }\end{array}$ & $\begin{array}{l}\text { Low-Income } \\
\text { Countries }\end{array}$ \\
\hline Annual GDP (USD) & USD 20 Trillion & USD 75 Billion \\
Average income per year & USD 51,000 & < USD 6000 \\
Percentage Expenditure on health & $17 \%$ & $6 \%$ \\
National expenditure on eye health & USD I50 million & USD 50 million \\
$\begin{array}{l}\text { per year } \\
\text { Cost of corneal cross linking per eye }\end{array}$ & USD 4000 & USD 300 \\
Average cost of a specialized RGP lens & USD 1000 & USD 600 \\
Cost of corneal transplant per eye & USD 13,000 & USD 5000 \\
\hline
\end{tabular}

Abbreviations: RGP, rigid gas permeable; USD, United States Dollar. contact lens clinic in Nairobi, Kenya over a 5-year period (2014 to 2019) were reviewed. All records of neophyte keratoconus patients who were examined and fitted with RGP or scleral contact lenses and those referred with existing corrections were included. Records of patients with missing data or with a history of corneal surgery, including penetrating keratoplasty (PK), or other active ocular diseases were excluded from the study. Patient demographic information, viz. age, gender, ethnicity and associated clinical conditions were extracted. The clinical diagnosis recorded was based on slit-lamp biomicroscope findings (including apical corneal protrusion, Fleischer's ring, Vogt's striae, stromal thinning) and keratometry measurements. Horizontal and vertical visible iris diameters, pupil diameters and refraction findings were used in contact lens selection and fitting. Study data included pre and post correction refractive errors (objective and subjective), visual acuity (pre and post correction), keratometry readings and type (RGP corneal or scleral) and parameters (diameter, base curve and power) of contact lenses prescribed.

Based on the steepest corneal curvature, keratoconus was classified into mild ( $\mathrm{K}<45$ diopters), moderate $(\mathrm{K}=45-52$ diopters) or severe ( $\mathrm{K}>52$ diopters $){ }^{29}$ Refractive power was classified in terms of spherical equivalent (SE) in each eye according to the method used by Cumberland et al. ${ }^{30}$ Emmetropia was defined as having dioptric power between -0.00 and 0.99 diopters (D). Myopia was classified as low $(-1.00$ to $-2.99 \mathrm{D})$, moderate $(-3.00 \mathrm{D}$ to $-5.99 \mathrm{D})$ or high $(\geq-6.00 \mathrm{D})$ and hypermetropia as mild $(+1.00 \mathrm{D}$ to $+2.99 \mathrm{D})$ and moderate to high $(\geq+3.00 \mathrm{D})$.

Statistical Package for the Social Sciences, Version 25 Software (SPSS Inc., Chicago, IL, USA) was used for analyses. Sociodemographic data were summarized using descriptive statistics, while inferential statistics were determined at the significance level of $\alpha=0.05$. The test for normality was performed using the Smirnov-Kolmogorov test at the significance level of $\propto=0.05$. To determine the effect of corneal RGP and scleral lenses on refractive error and visual acuity in keratoconic patients, paired sample $t$-tests and Wilcoxon signed-rank test were used for analysis with $95 \%$ confidence intervals.

\section{Ethical Consideration}

Informed consent to access the records for the retrospective chart review and gatekeeper permission to undertake the study at the study site was applied for and received by the designated clinical facility authority. All patients were 
de-identified as personal details were not included in the data analysis. Ethical approval was obtained from the Masinde Muliro University of Science and Technology Institutional Ethics Review Committee (MMUST IERC). A research permit was also granted from the National Commission for Science, Technology and Innovation (NACOSTI). The study was conducted in accordance with the tenets of the Helsinki Declaration.

\section{Results}

The total number of keratoconic patients who were prescribed contact lenses during the study period was 250 . After applying the exclusion criteria, data from 124 patients (195 eyes) were analyzed. The mean age of the patients who presented with $\mathrm{KC}$ was $20.86 \pm 9.50$ years (9-58 years) with 58.9\% (73) being males and $41.1 \%$ (51) females. Patients with manifested bilateral $\mathrm{KC}$ accounted for $57.3 \%$ of the sample (71), while $26.6 \%$ (33) and $16.1 \%$ (20) of patients had $\mathrm{KC}$ in the right and left eye, respectively. The majority of the patients were African (91.1\%) and the remaining were Asian (8.9\%). Most of the patients (74.2\%) did not report associated conditions, even though $25.8 \%$ (31) were found to have allergy signs. Poor vision was the dominant presenting complaint [blurred vision (31.5\%), general reduced vision $(24.2 \%)$, pain and reduced vision $(8.9 \%)]$. Other complaints included halos and squinting (16\%), contact lens intolerance $(12.9 \%)$ and prescription change $(5.6 \%)$. Majority of eyes $(92 \%)$ had mean K-values above 50 dioptres, which suggested advanced to severe keratoconus. The mean K-reading in the flatter meridian was $50.86 \pm 5.86$ diopters in the right eye and $50.67 \pm 6.27$ diopters in the left eye (Table 2).

Thirteen keratoconic eyes (10.5\%) were fitted with scleral contact lenses while $111(89.5 \%)$ received corneal RGP contact lenses. Scleral lenses prescribed were both mini-scleral (diameter $14.5 \mathrm{~mm}$ to $18 \mathrm{~mm}$ ) and scleral (diameter $\geq 18.1 \mathrm{~mm}$ ) lens designs. RGP lenses were fitted with a wide range of parameters being prescribed as shown in Table 3.

\section{Visual Acuities}

As shown in Table 4, the maximum unaided visual acuity amongst the 124 patients was $1.0 \pm 0.19 \operatorname{logMAR}$ (median: $1.0 \log$ MAR; range: 0.3 to $1.6 \log$ MAR) or $6 / 60$ with none of the patients achieving normal visual acuity (less than $6 / 9$ or $0.20 \log$ MAR). Correction with corneal and scleral RGP contact lenses resulted in improved visual acuity to a mean of $0.18 \pm 0.17$ (median: 0.18 ; range: -0.1 to 0.6 ) or $6 / 6$. Eightyfive patients achieved visual acuity of $0.2 \log$ MAR or $6 / 9$. Figure 1 shows the distribution of unaided (a) and aided (b) visual acuity in keratoconic patients.

A paired sample $t$-test suggested that there was a significant improvement in the visual acuity of keratoconus patients from unaided visual acuity $(M=1.29, S D=0.20)$ to aided $(M=0.19, S D=0.17)$, after fitting of corneal RGP contact lenses; $t(110)=30.66, p=0.001$. Comparisons for scleral contact lenses were done using the Wilcoxon signedrank due to the few lenses fitted and the aided visual acuity $(\mathrm{Mdn}=0.01)$ was found to be significantly higher than before fitting contact lenses $(\mathrm{Mdn}=1.06) \mathrm{Z}(12)=3.192, p=0.01$.

\section{Refractive Errors}

The mean refractive error (spherical equivalent) before contact lens fitting was $-9.43 \pm 2.37$ diopters (median: -9.00 ; range: -13.75 to -4.00 ). The post-fitting uncorrected refractive errors had a mean of $=-0.41 \pm 0.78$ diopters (median: 0.00 ; range: $-3.50 \mathrm{D}$ to $3.50 \mathrm{D}$ ). The majority of patients were high myopes in unaided refraction and approximately neutral refractive errors (plano \pm 0.50 ) with contact lenses as shown in Figure 2.

There was a significant reduction in the refractive status of the eyes $(M-0.45721, S D=0.81)$ following RGP corneal contact lens fitting $(\mathrm{M}-9.80, \mathrm{SD}=4.46)$, $\mathrm{t}(110)=21.15, p=0.001$.

The data on scleral RGP lenses were not normally distributed and the Wilcoxon signed-rank test was used for analysis and median values noted. The refractive change after correction with scleral lenses $(\mathrm{Mdn}=0.02)$ was statistically significantly higher than before fitting of

Table 2 Keratometric Profile of Patient Eyes $(n=195)$

\begin{tabular}{|l|l|l|l|l|l|l|l|}
\hline & & Range & Mode & Minimum & Maximum & Mean & Standard Deviation \\
\hline Right eye & Flatter & 26.30 & 52.00 & 41.50 & 67.80 & 50.86 & 5.86 \\
& Steeper & 35.10 & & 43.70 & 68.80 & 54.68 & 6.53 \\
\hline Left eye & Flatter & 35.00 & 54.00 & 34.60 & 69.60 & 50.67 & 6.27 \\
& Steeper & 33.50 & & 34.00 & 67.50 & 53.68 & 6.48 \\
\hline
\end{tabular}


Table 3 Scleral and Corneal RGP Lens Parameters Dispensed to Keratoconic Patients

\begin{tabular}{|l|l|l|l|}
\hline Contact Lens Parameter & Minimum & Maximum & Mode \\
\hline Corneal lens diameter & $7.5 \mathrm{~mm}$ & $10.2 \mathrm{~mm}$ & $9.0 \mathrm{~mm}$ \\
Corneal lens base curve & $4.2 \mathrm{~mm}$ & $7.2 \mathrm{~mm}$ & $6.4 \mathrm{~mm}$ \\
Scleral lenses diameter & $14.5 \mathrm{~mm}$ & $18.1 \mathrm{~mm}$ & $16.5 \mathrm{~mm}$ \\
Scleral lenses SAG & $3500 \mu \mathrm{m}$ & $4900 \mu \mathrm{m}$ & $4200 \mu \mathrm{m}$ \\
Lens Power (Spherical Equivalent) & $-8.25 \mathrm{D}$ & $-13.75 \mathrm{D}$ & $-7.50 \mathrm{D}$ \\
\hline
\end{tabular}

Abbreviations: D, diopters; $\mu \mathrm{m}$, microns.

Table 4 Distribution of Patients According to the Severity of Unaided VA and Aided VA When Corrected with Corneal and Scleral RGP Contact Lenses

\begin{tabular}{|l|l|l|l|l|}
\hline \multirow{4}{*}{} & \multicolumn{4}{|l|}{ Visual Acuity Categories } \\
& \multicolumn{2}{|l|}{ Snellen (logMAR) } \\
\cline { 2 - 5 } & Normal & Moderate & Blindness & $\begin{array}{l}\text { Severe } \\
\text { Blindness }\end{array}$ \\
\hline & $6 / 6-6 / 12$ & $6 / 18-6 / 60$ & $6 / 60-3 / 60$ & $3 / 60-1 / 60$ \\
$(00-0.1)$ & $(0.3-0.5)$ & $(1.0-1.3)$ & $(1.3-1.6)$ \\
& 120 & 4 & - \\
$\begin{array}{l}\text { Unaided visual acuity } \\
\text { Visual acuity with } \\
\text { corneal RGP lenses }\end{array}$ & 108 & 3 & - & - \\
$\begin{array}{l}\text { Visual acuity with } \\
\text { scleral RGP lenses }\end{array}$ & 13 & - & - & - \\
\hline
\end{tabular}

the contact lenses $(\mathrm{Mdn}=-8.00), \mathrm{Z}(11)=3.00, p=0.001$ as presented in Table 5 .

\section{Discussion}

As healthcare utilization depends on income status, in resource limited contexts, the high cost of eye care services and appliances makes them inaccessible to the average citizen. ${ }^{26,31}$ The increasing demands for specialized eye care services leads to procurement of more sophisticated diagnostic and management equipment in most middle- and high-income country practices. However, in low-income contexts, utilizing costly, imported gold-standard equipment and associated clinical protocols for conditions such as keratoconus remains out of financial reach of the majority of practices. Plagued by volatile economic climates, lack of local manufacturing capacity and rising import costs associated with high tech, advanced clinical equipment, the majority of optometry practices in low-income countries are forced to practice with basic diagnostic equipment. The results of this study reflect the profile of patients seen within typical low-income practice settings.
The mean age of presentation of patients included in the study was 20.86 years, which is the age where the younger generation typically commence with their productive adult work-life. The study by Toprak et $\mathrm{al}^{32}$ suggests that there often exists a delay between the age of onset and presentation for care in $\mathrm{KC}$ patients. The age of presentation in our study is similar to studies conducted in Nepal, ${ }^{2}$ Kenya, ${ }^{9} \operatorname{Iran}^{33}$ and Malaysia ${ }^{34}$ and slightly lower than studies in Ghana ${ }^{7}$ and South Africa. ${ }^{35}$ The concern with the widespread late presentation is that recent studies indicate that the onset of $\mathrm{KC}$ may be as young as 4 years of age ${ }^{36}$ with rapid progression during puberty. ${ }^{37}$ Despite the expected negative impact on education and daily living functions experienced by these young individuals, they continue to endure reduced visual morbidity challenges for many years before seeking care. Possible reasons could include the general lack of access to eye care services, inadequate health worker skills to detect $\mathrm{KC}$ and refer children seen at lower levels of the health system and high private consultation and contact lenses costs. Corrective interventions could include an awareness initiative targeted at the high-risk age groups and health worker training in $\mathrm{KC}$ screening and referral.

The finding of more males using contact lenses in the study suggests that males are more affected by keratoconus than females, which is similar to findings in many studies. ${ }^{7-9,38}$ However, there is currently no consensus as other research revealed higher prevalence in females ${ }^{32,35}$ or no significant difference between genders. ${ }^{39}$ The current study could highlight contexts where males are more culturally, academically and economically empowered than females (38), which enables them to more easily access and afford healthcare services.

Most patients (57.3\%) had contact lenses fitted in both eyes at initial consultation, although it is commonly known that $\mathrm{KC}$ manifests in one eye before the other. ${ }^{14}$ This could mean that patients in this study presented only when the disease progressed to the level where functionality was more seriously affected. The almost similar mean keratometric readings between the right and left eyes at presentation were also found in studies in Ghana and Nepal. ${ }^{2,7}$ Unilateral fittings could be due to the inability to afford purchasing both lenses together or forme fruste $\mathrm{KC}$ being undetected in the other eye due to a lack of more sophisticated diagnostic equipment as also postulated by Toprak et al. ${ }^{32}$

The chief complaint of most patients on presentation was blurred vision. This was expected as the symptom of blurred vision was previously cited as the chief presenting 

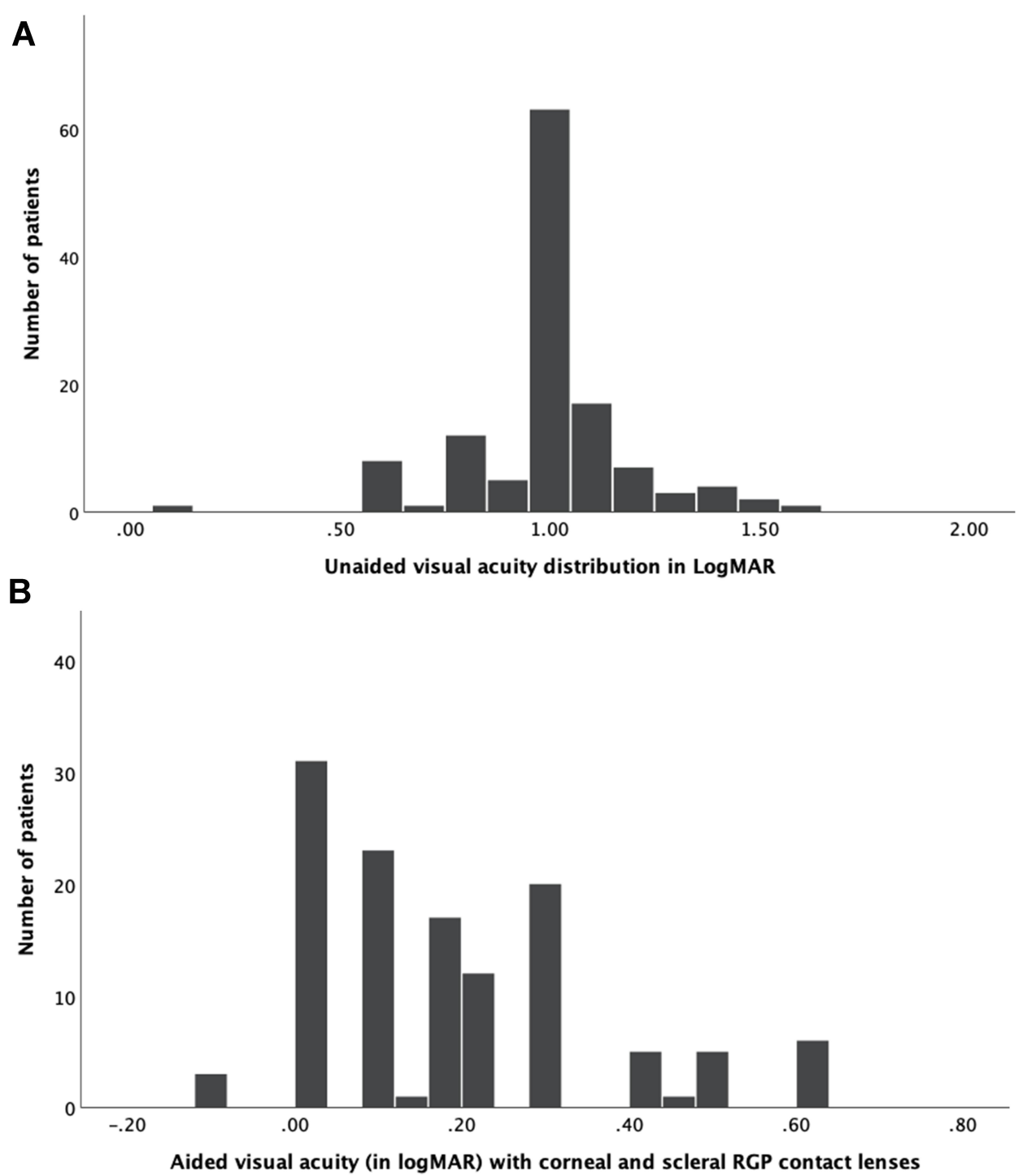

Figure I Histogram showing the distribution of unaided $(\mathbf{A})$ and aided $(\mathbf{B})$ visual acuity in keratoconic patients.

complaint amongst $\mathrm{KC}$ patients in studies conducted in Kenya. ${ }^{9,10}$ However, Doreen et al ${ }^{7}$ reported that the majority of patients in their study in Ghana complained of itching as the chief complaint. In this study, it could be that since patients presented when the $\mathrm{KC}$ was at an advanced stage with significant vision reduction, allergic complaints were less debilitating and hence of less concern as compared to reduced vision. Additionally, patients may have visited local clinics and were treated for the allergy without consideration been given to the possible association between allergic conditions such as vernal keratoconjunctivitis (VKC) and KC. It is recommended that training programmes on the association between $\mathrm{VKC}$ and $\mathrm{KC}$ be designed and implemented at clinic level for early $\mathrm{KC}$ detection.
The keratometric values on presentation fell mainly within the advanced and severe disease classification range, as was found in other studies. ${ }^{2,40}$ Consequently, the steeper corneal curvatures have negative treatment implications, as the option for interventions to retard the progression of the disease, such as CXL, may no longer be viable. Additionally, the severe $\mathrm{KC}$ will require more specialized contact lens designs, which have greater financial implications.

Similar to other studies ${ }^{2}$ conducted in low-income countries, an overwhelming majority of patients were fitted with corneal RGP contact lenses as opposed to scleral contact lenses (Table 5). This mode of correction for patients having advanced and severe $\mathrm{KC}$ is in contrast to protocols in developed countries where there is growing usage of scleral contact lenses, cited to provide benefits 

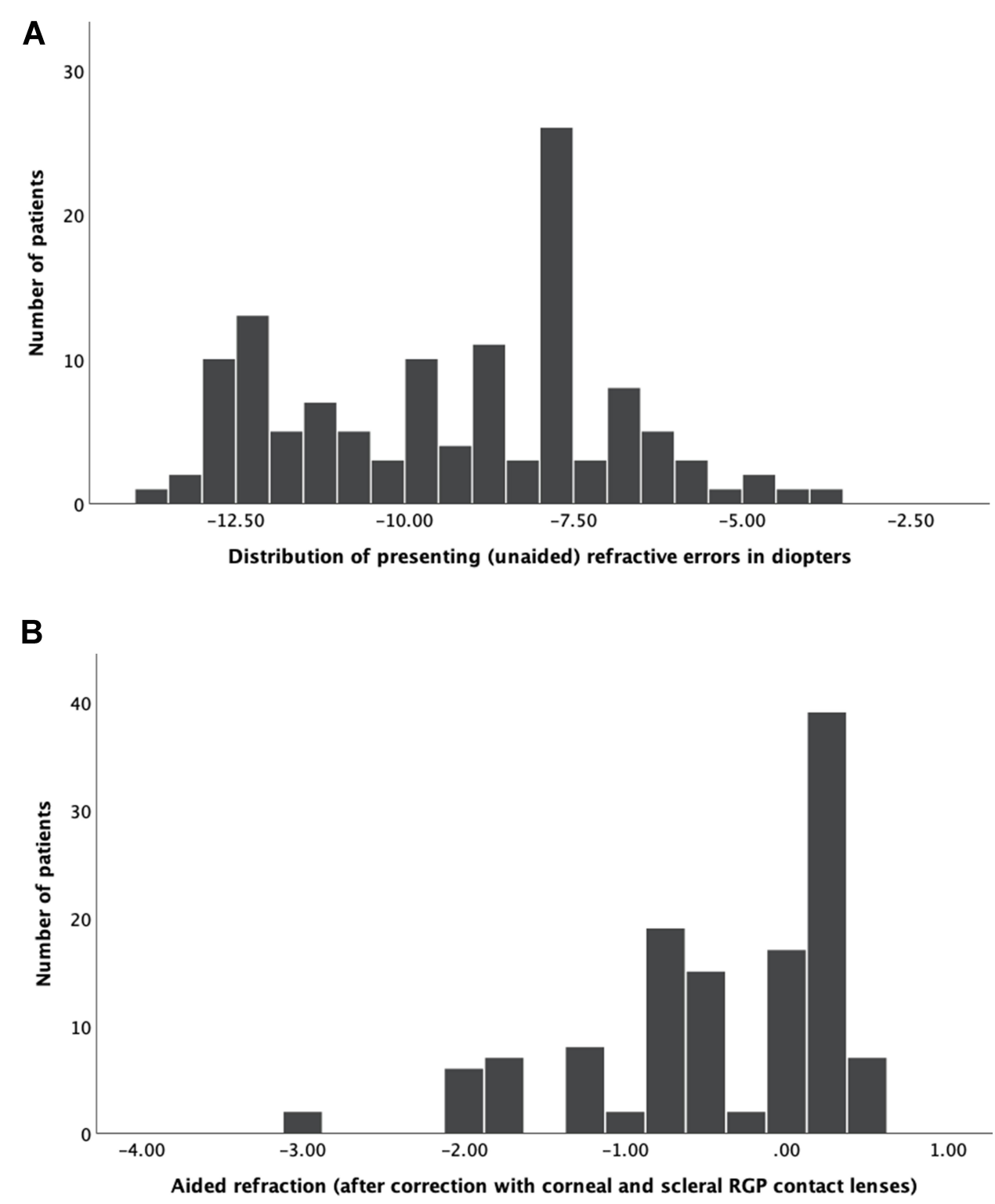

Figure 2 Histogram showing the distribution of presenting $(\mathbf{A})$ and corrected refractive errors (B).

such as better comfort as compared to corneal lenses. ${ }^{28}$ Cost differentiation could explain the high use of corneal lenses, which average USD250 as compared to scleral lenses which is approximately USD1000. Scleral lenses will therefore be out of the financial reach of the majority in low-income countries, such as Kenya, with an average monthly income of $\sim$ USD500. ${ }^{26}$

The lens parameters fitted in this study reveal that a practitioner in a low-income context can successfully fit the majority of their patients with a keratoconic fitting lens set with base curves ranging $\sim 4.3$ to $7.3 \mathrm{~mm}$ and just 2 diameter options $(9.00 \mathrm{~mm}$ and $10.2 \mathrm{~mm})$ in a range of powers increasing with lens steepness. Noting the financial constraints, purchasing fitting lens sets with commonly utilized parameters will make the practice inventory costs for $\mathrm{KC}$ patient management more affordable for the practitioners. Scleral lenses could be procured on an individual basis to manage patients, with the financial means, who have steep corneal curvatures and advanced cone characteristics. $^{8}$

Visual acuity is one of the most important parameters impacting on the quality of life of keratoconic patients. ${ }^{41}$ Improved visual acuity from blindness classification (Figure 1A) to normal vision status (Figure 1B) after RGP contact lens fitting highlights the positive impact of contact lenses as a $\mathrm{KC}$ management option. Our study is in agreement with other studies ${ }^{2,34,42-44}$ that reported consistent visual improvement due to contact lenses 
Table 5 Patient Distribution According to Severity of Unaided and Aided Refractive Errors (RE) and Mean (Median) Pre and Post Fitting Refractive Error Findings

\begin{tabular}{|c|c|c|c|c|c|c|c|c|c|}
\hline & \multicolumn{6}{|c|}{ Severity of RE } & \multicolumn{2}{|c|}{ Mean RE Findings (Median) } & \multirow[t]{3}{*}{ p-value } \\
\hline & \multicolumn{3}{|c|}{ Myopia } & \multirow[t]{2}{*}{ Emmetropia } & \multicolumn{2}{|c|}{ Hyperopia } & Unaided & Aided & \\
\hline & $a^{*}$ & $\mathbf{b}^{*}$ & $c^{*}$ & & $\mathbf{e}^{*}$ & $f^{*}$ & - & - & \\
\hline Unaided & I & 9 & 114 & 0 & - & 0 & & & \\
\hline RE & & & & & & & & & \\
\hline Corneal RGP wearers & 23 & 8 & - & 80 & - & - & $-9.80 \mathrm{D} \pm 4.468$ & $-0.457 \mathrm{D} \pm 0.80$ & $0.00 \mathrm{I}$ \\
\hline Scleral RGP wearers & - & - & - & 13 & - & - & $(-8.00 \mathrm{D})$ & $(0.02 \mathrm{D})$ & 0.001 \\
\hline
\end{tabular}

Notes: *Myopia was classified into low (a), moderate (b) and high (c) and hyperopia into mild (e) and moderate to high (f).

management. Patients who used the lower cost corneal RGP contact lenses achieved similar corrected visual acuity as those fitted with scleral lenses. The achievement of 6/6 VA, combined with the financial saving with the RGP corneal lenses, may motivate patients to compromise on the benefit of the initial lens comfort achieved with scleral lenses. The similar visual acuity outcomes between corneal and scleral lenses highlight the ability of both lens designs to mask high amounts of irregular astigmatism in correcting the refractive errors. ${ }^{3}$

The majority of patients in our study had high myopia and astigmatism (presented as spherical equivalent) progressing to the level of blindness (Figure 2A). After lens correction, the magnitude of the refractive errors significantly $(p=0.001)$ reduced with both corneal and scleral lens designs (Figure 2B). The neutralizing ability of corneal RGP contact lenses was clearly demonstrated by the emmetropic status achieved by the majority of patients in the study. These results confirm findings from other studies, ${ }^{2,47}$ where corneal RGP contact lenses remarkably improved refractive conditions. Schornack et $\mathrm{al}^{45}$ demonstrated a dramatic improvement in refractive status among scleral lens wearers, as was found in this small study sample. These patients will also have the additional benefit of better comfort than that provided with corneal lenses. ${ }^{46}$

The increasing incidence of keratoconus and associated management costs can cause a socio-economic burden to patients, practitioners and governments ${ }^{47}$ in low-income contexts. Despite the limited resources, the results of this study demonstrate that with a basic keratometer, slit lamp, complimentary small measuring devices and limited trial contact lens sets, the majority of $\mathrm{KC}$ patients were able to achieve normal visual acuity and emmetropia with their corneal RGP contact lenses. These improvements, comparable to those achieved with more sophisticated and expensive equipment and lens options, will potentially make a markedly positive impact on the daily living functions of $\mathrm{KC}$ patients.

\section{Conclusion}

Having sophisticated, costly, gold-standard equipment with easily available access to the latest specialized contact lens designs is a practice scenario that young optometrists will hope to find themselves within. However, the reality in most low-income contexts is in stark contrast to this ideal, yet the desire to provide patients with the best possible outcomes remains paramount. Subsequent to the contact lens fitting, the affected children and young adults in this study will be able to engage within their education and work environments with normal visual functional abilities. Corneal RGP contact lenses, the more costeffective option, can be successfully fitted on the majority of keratoconic patients, aided by the availability of basic diagnostic equipment. The study affirms that despite resource limitations, practitioners can utilize their clinical skills and still achieve life-changing visual outcomes for their keratoconic patients.

\section{Study Limitations}

The limited number of scleral contact lenses fitted in our study was the major impediment to more rigorous comparative analysis between the two lens modalities. The nature of our data on scleral lenses further necessitated the use of non-parametric data analysis and median rather than mean values. Patients were sourced through a single referral facility which may not reflect the situation in other low-income countries with multiple referral centers for KC. Moreover, the nature of data collection did not consider patients' data on comfort which paves the way for future studies. 


\section{Acknowledgment}

The authors would like to thank Mrs. Zahra Rashid from Muthaiga Eye Clinic at Gertrude Children's Hospital, Nairobi for support in data collection.

\section{Disclosure}

The authors have no conflicts of interest to declare for this work.

\section{References}

1. Brautaset RL, Nilsson M, Miller WL, Leach NE, Tukler JH, Bergmanson JPG. Central and peripheral corneal thinning in keratoconus. Cornea. 2013;32(3):257-261. doi:10.1097/ ICO.0b013e31825240d7

2. Chaudhary M, Kandel H. Visual outcome in keratoconus with spherical rigid gas permeable contact lens. J Inst Med. 2017;39(3):8-11.

3. Cruz-Becerril A, Valdivia A, Peralta R, Domínguez-Fernández RN, Castro-Reyes MA. Prevalence of refractive errors in Mexican patients with keratoconus. Clin Optom. 2015;7:39-44. doi:10.2147/ OPTO.S80654

4. Roy S, Yadav S, Dasgupta T, Chawla S, Tandon R, Ghosh S. Interplay between hereditary and environmental factors to establish an in vitro disease model of keratoconus. Drug Discov Today. 2019;24(2):403-416. doi:10.1016/j.drudis.2018.10.017

5. Sharif R, Bak-Nielsen S, Hjortdal J, Karamichos D. Pathogenesis of keratoconus: the intriguing therapeutic potential of prolactin-inducible protein. Prog Retin Eye Res. 2018;67:150-167. doi:10.1016/j. preteyeres.2018.05.002

6. Omer K. Epidemiology of keratoconus worldwide. Open Ophthalmol J. 2018;12(1):289-299. doi:10.2174/1874364101812010289

7. Doreen D, Kobia-acquah E, Kumah DB, Ankamah E. Profile of keratoconus in selected eye clinics, accra: a retrospective study. Ophthalmol Vis Sci. 2017;1(1):8-16.

8. Munsamy AJ, Moodley VR, Naidoo P, et al. A frequency analysis of cone characteristics for the different stages of keratoconus. Afr Vis Eye Health. 2015;74(1):6. doi:10.4102/aveh.v74i1.302

9. Rashid ZA, Millodot M, Evans KSE. Characteristics of keratoconic patients attending a specialist contact lens clinic in Kenya. Middle East Afr J Ophthalmol. 2016;23(4):283-287. doi:10.4103/0974-9233.194074

10. Chen MC, Kunselman AR, Stetter CM, Hannush SB, Roberts BW. Corneal transplantation at Tenwek Hospital, Kenya, East Africa: analysis of outcomes and associated patient socioeconomic characteristics. PLoS One. 2017;12(10):e0187026. doi:10.1371/journal.pone. 0187026

11. Cavas-Martínez F, Fernández-Pacheco DG, Parras D, Cañavate FJF, Bataille L, Alió J. Study and characterization of morphogeometric parameters to assist diagnosis of keratoconus. Biomed Eng. 2018;17(Suppl 1):161.

12. Ferdi AC, Nguyen V, Gore DM, Allan BD, Rozema JJ, Watson SL. Keratoconus natural progression: a systematic review and meta-analysis of 11529 eyes. Ophthalmology. 2019;126 (7):935-945. doi:10.1016/j.ophtha.2019.02.029

13. Graham R. Facing the crisis in human resources for eye health in sub-Saharan Africa. Community Eye Health. 2017;30(100):85-87.

14. Shi Y. Strategies for improving the early diagnosis of keratoconus. Clin Optom. 2016;8:13-21. doi:10.2147/OPTO.S63486

15. Goebels S, Käsmann-Kellner B, Eppig T, Seitz B, Langenbucher A. Can retinoscopy keep up in keratoconus diagnosis? Cont Lens Anterior Eye. 2015;38(4):234-239. doi:10.1016/j.clae.2015.01.015

16. Wu Y, Tan Q, Zhang W, et al. Rigid gas-permeable contact lens related life quality in keratoconic patients with different grades of severity. Clin Exp Optom. 2015;98(2):150-154. doi:10.1111/cxo.12237
17. Martin R. Cornea and anterior eye assessment with placido-disc keratoscopy, slit scanning evaluation topography and scheimpflug imaging tomography. Indian J Ophthalmol. 2018;66(3):360-366. doi:10.4103/ijo.IJO_850_17

18. Sharma R, Titiyal JS, Prakash G, Sharma N, Tandon R, Vajpayee RB. Clinical profile and risk factors for keratoplasty and development of hydrops in North Indian patients with keratoconus. Cornea. 2009;28 (4):367-370. doi:10.1097/ICO.0b013e31818cd077

19. Amanzadeh K, Karimian F, Khanlari M. Management of keratoconus. J Ophthalmic Vis Res. 2012;7(4):341-346.

20. Barnett M, Mannis MJ. Contact lenses in the management of keratoconus. Cornea. 2011;30(12):1510-1516. doi:10.1097/ICO.0b $013 \mathrm{e} 318211401 \mathrm{f}$

21. Better Vision Guide. Corneal collagen crosslinking | CXL treatment and cost information. corneal collagen crosslinking. Available from: https://www.bettervisionguide.com/corneal-collagen-cross-linking/. Accessed June 6, 2020.

22. Xu K, Soucat A, Kutzin J, et al. WHO | public spending on health: a closer look at global trends. WHO; 2018. Available from: http:// www.who.int/health_financing/documents/health-expenditure-report -2018/en/. Accessed June 6, 2020.

23. The Eye Practice. Why does keratoconus treatment cost so much? Available from: https://www.theeyepractice.com.au/optometristsydney/keratoconus-treatment-cost.Accessed June 6, 2020.

24. A stranger gave me back my sight. Eagle Eye. Available from: https://www.eagleeye.co.ke/a-stranger-gave-me-back-my-sight/. Accessed June 6, 2020.

25. PricewaterCooperhouse. The Price of Sight the Global Cost of Eliminating Avoidable Blindness. PricewaterhouseCoopers; 2013.

26. Armstrong KL, Jovic M, Vo-Phuoc JL, Thorpe JG, Doolan BL. The global cost of eliminating avoidable blindness. Indian J Ophthalmol. 2012;60(5):475-480. doi:10.4103/0301-4738.100554

27. Bourne RRA, Flaxman SR, Braithwaite T, et al. Magnitude, temporal trends, and projections of the global prevalence of blindness and distance and near vision impairment: a systematic review and meta-analysis. Lancet Glob Health. 2017;5(9):e888-e897. doi:10.1016/S2214-109X(17)30293-0

28. Otchere H, Jones L, Sorbara L. The impact of scleral contact lens vault on visual acuity and comfort. Eye Contact Lens. 2018;44(Suppl 2):S54-S59. doi:10.1097/ICL.0000000000000427

29. Zadnik K, Barr JT, Edrington TB, et al. Baseline findings in the collaborative longitudinal evaluation of keratoconus (CLEK) study. Invest Ophthalmol Vis Sci. 1998;39(13):2537-2546.

30. Cumberland PM, Chianca A, Rahi JS. For the UK biobank eye and vision consortium. Accuracy and utility of self-report of refractive error. JAMA Ophthalmol. 2016;134(7):794-801. doi:10.1001/ jamaophthalmol.2016.1275

31. Ngugi AK, Agoi F, Mahoney MR, et al. Utilization of health services in a resource-limited rural area in Kenya: prevalence and associated household-level factors. PLoS One. 2017;12(2):e0172728. doi:10.1371/journal.pone.0172728

32. Toprak I, Yaylalı V, Yildirim C. A combination of topographic and pachymetric parameters in keratoconus diagnosis. Cont Lens Anterior Eye. 2015;38(5):357-362. doi:10.1016/j.clae.2015.04.001

33. Naderan M, Shoar S, Rezagholizadeh F, Zolfaghari M, Naderan M. Characteristics and associations of keratoconus patients. Cont Lens Anterior Eye. 2015;38(3):199-205. doi:10.1016/j.clae.2015.01.008

34. Mohd-Ali B, Muthiah P, Retnasabapathy S, Mohidin N. Clinical characteristics of keratoconus patients in Malaysia: a 5-year retrospective study from a cornea specialist centre in selangor (2008-2013). Cont Lens Anterior Eye. 2015;38:25-e25. doi:10.1016/j.clae.2014.11.031

35. Chetty E, Rubin A. Preliminary demographics for patients with keratoconus attending a university-based clinic in Johannesburg, South Africa. Afr Vis Eye Health. 2019;78(1):5. doi:10.4102/aveh. v78i1.472 
36. Olivo-Payne A, Abdala-Figuerola A, Hernandez-Bogantes E, PedroAguilar L, Chan E, Godefrooij D. Optimal management of pediatric keratoconus: challenges and solutions. Clin Ophthalmol. 2019;12 (13):1183-1191. doi:10.2147/OPTH.S183347

37. Gokul A, Patel DV, Watters GA, McGhee CNJ. The natural history of corneal topographic progression of keratoconus after age 30 years in non-contact lens wearers. Br J Ophthalmol. 2017;101(6):839-844. doi:10.1136/bjophthalmol-2016-308682

38. Abdu M, Binnawi K, Elmadina AE, Hassan R. Clinical profile of keratoconus patients in Sudan. Sudan J Ophthalmol. 2016;8(1):20. doi:10.4103/1858-540X.184235

39. Romero-Jiménez M, Santodomingo-Rubido J, Wolffsohn JS. Keratoconus: a review. Cont Lens Anterior Eye. 2010;33(4):157-166. doi:10.1016/j.clae.2010.04.006

40. KhabazKhoob M, Hashemi H, Yazdani K, Mehravaran S, Yekta A, Fotouhi A. Keratometry measurements, corneal astigmatism and irregularity in a normal population: the Tehran eye study. Ophthalmic Physiol Opt. 2010;30(6):800-805. doi:10.1111/j.1475-1313.2010.00732.x

41. Martin R, Ortiz-Toquero S, Perez S, Rodriguez G, Juan VD. Assessment of vision-related quality of life in keratoconus patients: influence of spectacles versus RGP contact lenses wear. Cont Lens Anterior Eye. 2018;1(41):S26. doi:10.1016/j.clae.2018.04.163
42. Aydin Kurna S, Altun A, Gencaga T, Akkaya S, Sengor T. Vision related quality of life in patients with keratoconus. $J$ Ophthalmol. 2014;2014:694542. doi:10.1155/2014/694542

43. Opačić D, Miljak S, Ćuruvija-Opačić K. The level of improvement of visual acuity in high corneal astigmatism with rigid gas permeable contact lenses. Coll Antropol. 2015;39(1):229-232.

44. Abdu M, Mohd Ali B, Norhani M, Binnawi K. Corrected visual functions in keratoconus patients with rigid gas-permeable contact lens and its association with cone. Sudan J Ophthalmol. 2015;7 (2):48-52. doi:10.4103/1858-540X.169436

45. Schornack M, Nau C, Nau A, Harthan J, Fogt J, Shorter E. Visual and physiological outcomes of scleral lens wear. Cont Lens Anterior Eye. 2019;42(1):3-8. doi:10.1016/j.clae.2018.07.007

46. Yan P, Kapasi M, Conlon R, et al. Patient comfort and visual outcomes of mini-scleral contact lenses. Can J Ophthalmol. 2017;52 (1):69-73. doi:10.1016/j.jcjo.2016.07.008

47. Woodward MA, Blachley TS, Stein JD. The association between sociodemographic factors, common systemic diseases, and keratoconus: an analysis of a nationwide healthcare claims database. Ophthalmology. 2016;123(3):457-465. doi:10.1016/j.ophtha.2015.10.035
Clinical Optometry

\section{Publish your work in this journal}

Clinical Optometry is an international, peer-reviewed, open access journal publishing original research, basic science, clinical and epidemiological studies, reviews and evaluations on clinical optometry. All aspects of patient care are addressed within the journal as well as the practice of optometry including economic and business analyses. Basic and clinical research papers are published that cover

Submit your manuscript here: https://www.dovepress.com/clinical-optometry-journal

\section{Dovepress}

all aspects of optics, refraction and its application to the theory and practice of optometry. The manuscript management system is completely online and includes a very quick and fair peer-review system, which is all easy to use. Visit http://www.dovepress.com/ testimonials.php to read real quotes from published authors. 